\title{
Impact of Gas(less) Laparoscopy and Laparotomy on Peritoneal Tumor Growth and Abdominal Wall Metastases
}

\author{
Nicole D. Bouvy, M.D., Richard L. Marquet, Ph.D., Hans Jeekel, M.D., Ph.D.,
} and $H$. Jaap Bonjer, M.D., Ph.D.

From the Department of Surgery, University Hospital Dijkzigt, Rotterdam, The Netherlands

\section{Objective}

A tumor model in the rat was used to study peritoneal tumor growth and abdominal wall metastases after carbon dioxide $\left(\mathrm{CO}_{2}\right)$ pneumoperitoneum, gasless laparoscopy, and laparotomy.

\section{Summary Background Data}

The role of laparoscopic resection of cancer is under debate. Insufflation of the peritoneal cavity with $\mathrm{CO}_{2}$ is believed to be a causative factor in the development of abdominal wall metastases after laparoscopic resection of malignant tumors.

\section{Methods}

In the solid tumor model, a lump of 350-mg CC-531 tumor cells was placed intraperitoneally in rats having $\mathrm{CO}_{2}$ pneumoperitoneum $(n=8)$, gasless laparoscopy $(n=$ $8)$, or conventional laparotomy $(n=8)$. After 20 minutes, the solid tumor was removed through a laparoscopic port or through the laparotomy. In the cell seeding model, $5 \times 10^{5}$ CC-531 cells were injected intraperitoneally before $\mathrm{CO}_{2}$ pneumoperitoneum $(n=12)$, gasless laparoscopy $(n=12)$, or laparotomy $(n=12)$. All operative procedures lasted 20 minutes. After 6 weeks, in the solid tumor model and after 4 weeks in the cell seeding model, tumor growth was scored semiquantitatively. All results were analyzed using the analysis of variance.

\section{Results}

In the solid tumor model, peritoneal tumor growth in the laparotomy group was greater than in the $\mathrm{CO}_{2}$ pneumoperitoneum group $(\mathrm{p}<0.01)$. Peritoneal tumor growth in the $\mathrm{CO}_{2}$ group was greater than in the gasless group $(p<0.01)$. The size of abdominal wall metastases was greater at the port site of extraction of the tumor than at the other port sites $(p<0.001)$. In the cell seeding model, peritoneal tumor growth was greater after laparotomy in comparison to $\mathrm{CO}_{2}$ pneumoperitoneum $(\mathrm{p}<0.02)$. Peritoneal tumor growth in the $\mathrm{CO}_{2}$ group was greater than in the gasless group $(\mathrm{p}<0.01)$. The port site metastases in the $\mathrm{CO}_{2}$ group were greater than in the gasless group $(p<0.01)$.

\section{Conclusions}

The following conclusions can be made: 1) that direct contact between solid tumor and the port site enhances local tumor growth, 2) that laparoscopy is associated with less 
intraperitoneal tumor growth than laparotomy, and 3) that insufflation of $\mathrm{CO}_{2}$ promotes tumor growth at the peritoneum and is associated with greater abdominal wall metastases than gasless laparoscopy.

Laparoscopic-assisted colectomy has been shown to be technically feasible and associated with a low level of morbidity. ${ }^{1-3}$ Until now, the total number of patients having laparoscopic colorectal resections is small in comparison to the wide extent of application of laparoscopic cholecystectomy. ${ }^{4}$ The technical complexity, long duration, and high financial costs of laparoscopic colorectal procedures probably are responsible for the slow expansion of this type of surgery. ${ }^{5}$ However, the most impeding factor seems the general concern about the feasibility of laparoscopic techniques to treat malignant disease. ${ }^{6}$ More than 20 publications report 30 tumor recurrences at the site of cannula insertion or at the extraction (EXT) site of the specimen. ${ }^{7,8}$ The interval between operation and recurrence after laparoscopic resection of colorectal malignancies ranged from 3 to 26 months. Despite the fact that most of the reported cases have occurred after resection of either Dukes' B, C, or D disease, there also have been reports of metastatic spread of tumor after attempted curative resection of Dukes A lesions. ${ }^{7}$

Tumor recurrence in the abdominal wall after open surgery has been reported rarely. In a series of 1603 conventional resections of colorectal cancer, abdominal wall metastases developed in 11 patients in the laparotomy incision or at the insertion site of a drainage tube, accounting for a rate of $0.6 \% .^{9}$ Although the true incidence of abdominal wall metastases after open resection of colorectal cancer is unknown, abdominal wall metastases after laparoscopic resections of colorectal cancer appear to be more prevalent. Thus, before the clinical use of laparoscopic techniques to remove malignant tumors, experimental studies are necessary to determine the effects of different operative approaches on tumor biology. We developed a solid tumor model in rats to study direct implantation of tumor cells in the EXT site. A cell seeding model was used to mimic the clinical situation of free viable intraperitoneal tumor cells.

The purpose of this study is to assess peritoneal tumor growth and abdominal wall metastases in rats after laparotomy, laparoscopy using carbon dioxide $\left(\mathrm{CO}_{2}\right)$, or gasless laparoscopy with mechanical elevation of the abdominal wall.

\section{MATERIALS AND METHODS}

\section{Animals}

Male rats of the inbred WAG strain, weighing 200 to $300 \mathrm{~g}$ and aged 4 to 5 months, were obtained from Har-

Address reprint requests to Hendrik J. Bonjer, M.D., Ph.D., Department of Surgery, University Hospital Dijkzigt, Dr Molewaterplein 40, 3015 GD Rotterdam, The Netherlands.
lan-CPB, Austerlitz, The Netherlands. Rats were bred under specific pathogen-free conditions. The animals were kept under standard laboratory conditions (temperature, 20 to $24 \mathrm{C}$; relative humidity, $50 \%$ to $60 \%, 12$ hours light -12 hours dark) and were fed a standard laboratory diet (Hope Farms, Woerden, The Netherlands) with free access to water and food before and after surgery. The protocols were approved by the Committee on Animal Research of the Erasmus University, Rotterdam, The Netherlands.

\section{Tumor}

CC-531 is a 1,2-dimethylhydrazine-induced, weakly immunogenic, moderately differentiated colon adenocarcinoma, transplantable in syngeneic WAG rats. This tumor is weakly immunogenic as determined by the immunization-challenge method of Prehn and Main. ${ }^{10}$ The tumor was maintained in vitro in RPMI-1640 medium supplemented with $5 \%$ fetal calf serum (virus and mycoplasm screened), $1 \%$ penicillin $(5000$ units $/ \mathrm{mL}), 1 \%$ streptomycin (5000 units $/ \mathrm{mL})$, and $1 \%$ L-glutamine (200 mmol). All supplements were obtained from Gibco (Paisley, United Kingdom). Before their use, cells were trypsinized (5 minutes, $37 \mathrm{C}$ ), centrifuged (5 minutes, 3000 rpmg), resuspended in RPMI-1640, and counted. Viability was measured with trypan-blue exclusion $(0.3 \%$ in a $0.9 \%$ sodium chloride solution). Viability always exceeded 95\%. All tumor cells were injected within 4 hours after being obtained.

To grow solid tumor, $1 \times 10^{8} \mathrm{CC}-531$ tumor cells were injected in the right and left flanks of syngeneic WAG rats. After 6 weeks, the tumor volume in both flanks reached a volume of $2.5 \mathrm{~cm}^{3}$, and the tumor mass was isolated aseptically with a scalpel from the outer membrane of the main lesion. Subsequently, the tumor was cut into pieces of $350 \mathrm{mg}$, immersed in a culture solution, and stored at $4 \mathrm{C}$ until the solid lump was placed intraabdominally. All lumps were placed intra-abdominally within 1 to 4 hours after collection of the solid CC-531 tumor from syngeneic WAG rats.

\section{Operative Procedures}

After being anesthetized with atropine $0.05 \mathrm{mg} / \mathrm{kg}$ (Centrafarm, Etten-Leur, The Netherlands), domitor 0.25 $\mathrm{mg} / \mathrm{kg}$ intramuscularly (SmithKline Beecham, Zoetermeer, The Netherlands), and ketalin $40 \mathrm{mg} / \mathrm{kg}$ intraperitoneally (Apharmo b.b., Arnhem, The Netherlands), the ab- 
domen of the animals was shaved. The rat was secured to the operating table with adhesive tape in a supine position, and the abdomen was cleaned with $70 \%$ alcohol and dried with gauze. The laparoscope, camera, and attached cables were held at the desired angle by a flexible arm. The surgeon was sitting at one end of the operating table facing the video monitor. The instruments, trocars, and laparoscope were cleaned with $70 \%$ alcohol before and after surgery.

The rats undergoing laparoscopy had a 5-mm skin incision in the midline of the abdomen at two thirds between the xiphoid process and the pubis. A 5-mm laparoscopic sheath with insufflation side port was introduced after an introduction of a 4-mm arthroscope. Two other 5-mm ports were introduced under direct vision; one in the upper left quadrant and one in the upper right quadrant of the abdomen. Rats that had a pneumoperitoneum were insufflated with $\mathrm{CO}_{2}$ to a maximum pressure of $6 \mathrm{mmHg}, 10$ minutes through an opened trocar in the upper left quadrant and 10 minutes through the opened trocar in the upper right quadrant (6.4 $\mathrm{L} \mathrm{CO}_{2}$ in total) to mimic normal turbulence, which occurs in clinical setting.

Mechanical elevation of the abdomen was established by three sutures attaching the trocars to a metal arm positioned over the rat. The trocar holes in both laparoscopy groups were closed with one suture.

In the laparotomy group, a $5-\mathrm{cm}$ abdominal skin incision was made in the midline of the abdomen. The abdomen was closed in one layer with a running suture. The operative time was 20 minutes in all procedures. To terminate anesthesia, antisedan $2 \mathrm{mg} / \mathrm{kg}$ intramuscularly (SmithKline Beecham) was given.

\section{Experimental Groups}

\section{Solid Tumor Model}

Twenty-four rats participated in this experiment; 8 rats (group I) had a $\mathrm{CO}_{2}$ pneumoperitoneum, 8 rats had mechanical elevation of the abdominal wall (group II), and 8 rats were subjected to a midline laparotomy (group III). In the laparoscopic groups, a lump of CC-531 solid colon carcinoma, weighing $350 \mathrm{mg}$, was introduced through the EXT port in the upper left quadrant of the abdomen and placed between two lobes of the liver. An extra 5-mm site port was placed in the upper right quadrant. The 4$\mathrm{mm}$ scope was introduced through a $5-\mathrm{mm}$ port at the umbilicus.

In groups I and II, the solid tumor was identified laparoscopically and grasped with a 5-mm dissection clamp after 20 minutes. The trocar at the EXT site was withdrawn before extraction of the tumor. In group III, the lump also was placed between the liver and removed after 20 minutes through the midline incision. All animals were killed after 6 weeks. Abdominal wall metastases and intraperitoneal tumor growth were scored semiquantitatively. The scoring ranged from 0 to 5 per site and was assessed by two independent observers, according to the peritoneal cancer index described by Steller. ${ }^{11}$ In case of disagreement between the two observers, the score was averaged. A score of 0 indicated no presence of tumor, a score of 1 correlated with an estimated tumor diameter less than $0.5 \mathrm{~cm}$, a score of 2 with a tumor diameter between $0.5 \mathrm{~cm}$ and $1.0 \mathrm{~cm}$, a score of 3 with a tumor diameter between $1.0 \mathrm{~cm}$ and $2.0 \mathrm{~cm}$, a score of 4 with a tumor diameter between $2.0 \mathrm{~cm}$ and $3.0 \mathrm{~cm}$, and a score of 5 with a diameter exceeding $3.0 \mathrm{~cm}$. Abdominal wall metastases were defined as tumor growth in the subcutis or peritoneum at the site of an abdominal scar. The total tumor load of each rat was defined as the total of tumor growth at all intra-abdominal sites (e.g., kidney, liver, omentum, retroperitoneum, and scrotal fat).

\section{Cell Seeding Model}

In this experiment, $5 \times 10^{5} \mathrm{CC}-531$ tumor cells in 1.0$\mathrm{mL}$ RPMI-1640 medium were injected intraperitoneally along the inner left and right abdominal walls before each procedure. To ensure that the cells were injected intraperitoneally, the drop test was performed previous to tumor cell injection. In this test, a drop of saline solution is placed within the open lumen of the injection needle. As the needle enters the peritoneal cavity, the relative negative intra-abdominal pressure sucks the fluid through the needle. The rats were randomized between three groups. Twelve rats (group IV) had $\mathrm{CO}_{2}$ pneumoperitoneum, 12 rats (group V) had mechanic elevation of the abdominal wall, and 12 rats were subjected to laparotomy (group VI). After 4 weeks, all animals were killed, and tumor growth was scored semiquantitatively as mentioned above. Each of the following sites was scored separately: peritoneum and subcutis (abdominal wall metastases), kidney, liver, omentum, retroperitoneum, and scrotal fat. The total tumor load was defined as the sum of tumor growth at each site.

\section{Statistical Analysis}

The mean and the standard deviation of the collected data were calculated. To analyze the data for significant differences, the analysis of variance was used. To assess the presence of a normal distribution of the data, a histogram was made. Results were considered statistically significant at $\mathrm{p}<0.05$.

\section{RESULTS}

\section{Solid Tumor Model}

In a histogram, all results proved to be normally distributed. The results of assessment of abdominal wall metas- 


\section{Table 1. MEAN DIAMETER AND STANDARD DEVIATION OF THE ABDOMINAL WALL METASTASES AT DIFFERENT TROCAR SITES, AND MEAN TOTAL TUMOR LOAD AND STANDARD DEVIATION OF RATS HAVING $\mathrm{CO}_{2}$ PNEUMOPERITONEUM (GROUP I), GASLESS LAPAROSCOPY (GROUP II), AND LAPAROTOMY (GROUP III) IN THE SOLID TUMOR MODEL}

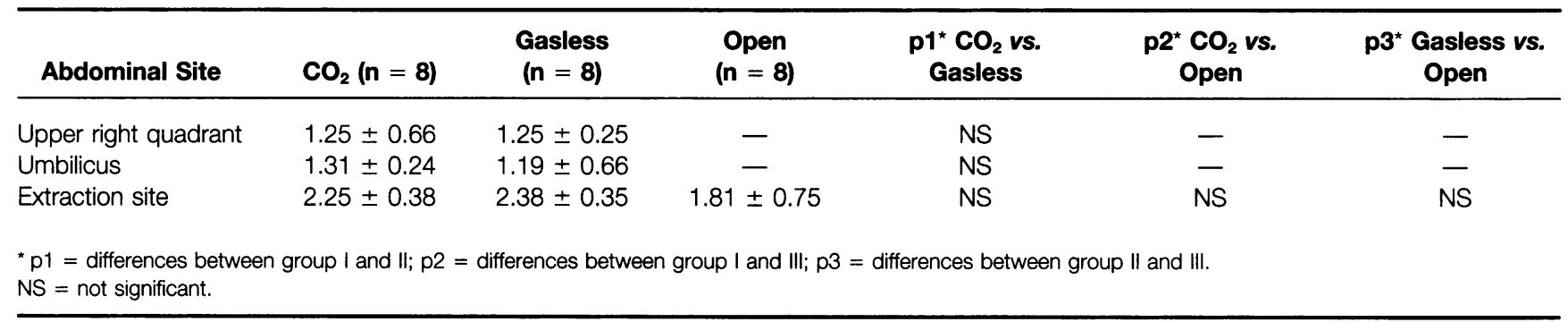

tases are listed in Table 1. Abdominal wall metastases developed in all rats having either $\mathrm{CO}_{2}$ or gasless laparoscopy. Abdominal wall metastases developed in only six of the eight rats having open surgery. Significant differences of abdominal wall metastases were not found between the $\mathrm{CO}_{2}$ pneumoperitoneum, gasless laparoscopy, and laparotomy group at the EXT site of the specimen. Comparison of the laparoscopic non-EXT sites (upper right quadrant versus umbilicus) also showed no significant differences. The size of the tumor at the EXT site was significantly greater than the tumor size at the other two sites in both the $\mathrm{CO}_{2}$ pneumoperitoneum group and the gasless laparoscopy group (both $\mathrm{p}<0.001$ ) (Table 2).

Diffuse and extensive tumor growth was found in all rats. At the kidney, liver, and scrotal fat, no significant differences were found after the three different operative procedures (Table 3). Tumor growth at the omentum and retroperitoneum in the gasless group was significantly less than in the laparotomy group and the $\mathrm{CO}_{2}$ pneumoperitoneum group $(p<0.01)$. Also, total peritoneal tumor load in the gasless laparoscopy group was significantly less than in the laparotomy group and the $\mathrm{CO}_{2}$ pneumoperitoneum group $(\mathrm{p}<0.01$ and $\mathrm{p}<0.001$, respectively).

\section{Cell Seeding Model}

In a histogram, all results proved to be distributed normally. Tumor growth in rats after $\mathrm{CO}_{2}$ pneumoperitoneum, gasless laparoscopy, and laparotomy are listed in Table 4.

Comparison of the $\mathrm{CO}_{2}$ pneumoperitoneum group and the gasless group showed significantly greater tumor deposits at the peritoneum at the trocar sites $(p<0.01)$. Furthermore, after $\mathrm{CO}_{2}$ pneumoperitoneum, the tumor growth at the omentum $(\mathrm{p}<0.001)$, the scrotal fat $(\mathrm{p}<$ $0.02)$, and the total tumor load ( $\mathrm{p}<0.001)$ were greater than after gasless laparoscopy. Differences of tumor growth at the other four abdominal sites were not significant.

Comparing tumor growth in rats after either laparotomy or $\mathrm{CO}_{2}$ pneumoperitoneum showed greater abdominal wall metastases in the laparotomy group as compared with the $\mathrm{CO}_{2}$ pneumoperitoneum group (peritoneum, $\mathrm{p}<$

\section{Table 2. MEAN DIAMETER AND STANDARD DEVIATION OF THE ABDOMINAL WALL METASTASES AT DIFFERENT TROCAR SITES OF RATS HAVING $\mathrm{CO}_{2}$ PNEUMOPERITONEUM (GROUP I) AND GASLESS LAPAROSCOPY (GROUP II) IN THE SOLID TUMOR MODEL}

\begin{tabular}{|c|c|c|c|c|c|c|}
\hline Group & URQ & UMB & EXT & $\begin{array}{c}\text { p1* URQ vs. } \\
\text { UMB }\end{array}$ & $\begin{array}{c}\text { p2* URQ vs. } \\
\text { EXT }\end{array}$ & $\begin{array}{c}\text { p3* UMB vs. } \\
\text { EXT }\end{array}$ \\
\hline $\mathrm{CO}_{2}$ & $1.25 \pm 0.66$ & $1.31 \pm 0.24$ & $2.25 \pm 0.38$ & NS & $<0.001$ & $<0.001$ \\
\hline Gasless & $1.25 \pm 0.25$ & $1.19 \pm 0.66$ & $2.38 \pm 0.35$ & NS & $<0.001$ & $<0.001$ \\
\hline
\end{tabular}


Table 3. MEAN TUMOR GROWTH AND STANDARD DEVIATION AT DIFFERENT ABDOMINAL SITES, AND MEAN TOTAL TUMOR LOAD AND STANDARD DEVIATION IN RATS HAVING $\mathrm{CO}_{2}$ PNEUMOPERITONEUM (GROUP I), GASLESS LAPAROSCOPY (GROUP II), AND LAPAROTOMY (GROUP III) IN THE SOLID TUMOR MODEL

\begin{tabular}{lcccccc}
\hline $\begin{array}{c}\text { Abdominal } \\
\text { Site }\end{array}$ & $\mathbf{C O}_{\mathbf{2}}$ (n= 8) & $\begin{array}{c}\text { Gasless } \\
(\mathbf{n}=\mathbf{8})\end{array}$ & $\begin{array}{c}\text { Open } \\
(\mathbf{n}=\mathbf{8})\end{array}$ & $\begin{array}{c}\mathbf{p 1}^{\star} \mathbf{C O}_{\mathbf{2}} \text { vs. } \\
\text { Gasless }\end{array}$ & $\begin{array}{c}\mathbf{p 2}^{*} \mathbf{C O}_{\mathbf{2}} \text { vs. } \\
\text { Open }\end{array}$ & $\begin{array}{c}\mathbf{p 3}^{*} \text { Gasless vs. } \\
\text { Open }\end{array}$ \\
\hline Kidney & $3.00 \pm 0.00$ & $3.25 \pm 0.46$ & $3.00 \pm 0.00$ & $\mathrm{NS}$ & $\mathrm{NS}$ & $\mathrm{NS}$ \\
Liver & $2.50 \pm 0.53$ & $2.63 \pm 0.52$ & $2.75 \pm 0.71$ & $\mathrm{NS}$ & $\mathrm{NS}$ & $\mathrm{NS}$ \\
Omentum & $2.50 \pm 0.93$ & $1.38 \pm 0.52$ & $2.38 \pm 0.52$ & $<0.01$ & $\mathrm{NS}$ & $<0.01$ \\
Retroperitoneum & $2.75 \pm 0.46$ & $1.25 \pm 0.46$ & $2.50 \pm 0.76$ & $<0.001$ & $\mathrm{NS}$ & $<0.01$ \\
Scrotal fat & $2.75 \pm 1.16$ & $2.25 \pm 0.46$ & $2.75 \pm 0.71$ & $\mathrm{NS}$ & $\mathrm{NS}$ & $<$ \\
Total tumor load & $13.50 \pm 1.2$ & $10.75 \pm 1.04$ & $13.13 \pm 1.20$ & $<0.001$ & $\mathrm{NS}$ & $<0.01$
\end{tabular}

${ }^{\star} \mathrm{p} 1$ = differences between group I and II; $\mathrm{p} 2$ = differences between group I and III; $\mathrm{p} 3=$ differences between group II and III. NS $=$ not significant.

0.02 ; subcutis, $\mathrm{p}<0.001$ ). Differences of tumor growth at the other five sites were not significant. The total peritoneal tumor load of rats after laparotomy was significantly greater than the total peritoneal tumor load after $\mathrm{CO}_{2}$ pneumoperitoneum $(\mathrm{p}<0.001)$.

Comparing gasless laparoscopy with open surgery showed greater abdominal metastases (peritoneum and subcutis, $\mathrm{p}<0.001$ ) in the open group. Tumor growth in the omentum, liver, scrotal fat, and total tumor load was less after gasless laparoscopy (all, $\mathrm{p}<0.01$ ).

\section{DISCUSSION}

Tumor recurrence in the abdominal wall after conventional resection for colorectal cancer has been reported infrequently. In recent years, several reports of trocar site recurrence after laparoscopic oncologic procedures have been published. ${ }^{6-8}$ These reports have caused major turmoil because abdominal wall metastases had been reported rarely after conventional laparoscopic colorectal resection. ${ }^{9}$ Abdominal wall metastases withhold many colorectal surgeons to use laparoscopic techniques to treat colorectal cancer. ${ }^{12}$ Because the pathogenesis of abdominal wall metastases is unresolved, basic scientific studies focusing on this topic are indicated.

The mechanism of the development of abdominal wall metastases can be explained in various ways. First, direct implantation of tumor cells at the trocar or EXT site is considered to play a major role. Direct implantation at the trocar site can occur when a laparoscopic instrument inadvertently has grasped the tumor during the laparoscopic procedure. When this instrument is withdrawn through the trocar, tumor cells can detach, adhere to the trocar, and implant at the trocar site during removal of

Table 4. MEAN TUMOR GROWTH AND STANDARD DEVIATION, AND MEAN TOTAL TUMOR LOAD AND STANDARD DEVIATION AT DIFFERENT ABDOMINAL SITES IN RATS HAVING $\mathrm{CO}_{2}$ PNEUMOPERITONEUM (GROUP IV), GASLESS LAPAROSCOPY (GROUP V), AND LAPAROTOMY (GROUP VI) IN THE CELL SEEDING MODEL

\begin{tabular}{|c|c|c|c|c|c|c|}
\hline $\begin{array}{l}\text { Abdominal } \\
\text { Site }\end{array}$ & $\begin{array}{c}\mathrm{CO}_{2} \\
(n=12)\end{array}$ & $\begin{array}{l}\text { Gasless } \\
(n=12)\end{array}$ & $\begin{array}{c}\text { Open } \\
(n=12)\end{array}$ & $\begin{array}{c}\mathrm{p1}^{*} \mathrm{CO}_{2} \text { vs. } \\
\text { Gasless }\end{array}$ & $\begin{array}{c}\mathrm{p}^{\star} \mathrm{CO}_{2} \text { vs. } \\
\text { Open }\end{array}$ & $\begin{array}{c}\text { p3* Gasless vs. } \\
\text { Open }\end{array}$ \\
\hline Peritoneum & $0.83 \pm 0.72$ & $0.00 \pm 0.00$ & $1.46 \pm 0.78$ & $<0.01$ & $<0.02$ & $<0.001$ \\
\hline Subcutis & $0.17 \pm 0.39$ & $0.00 \pm 0.00$ & $1.25 \pm 1.08$ & NS & $<0.001$ & $<0.001$ \\
\hline Kidney & $1.58 \pm 0.63$ & $1.25 \pm 0.58$ & $1.96 \pm 1.10$ & NS & NS & NS \\
\hline Liver & $0.67 \pm 0.49$ & $0.33 \pm 0.49$ & $1.13 \pm 0.80$ & NS & NS & $<0.01$ \\
\hline Omentum & $1.92 \pm 0.19$ & $0.58 \pm 0.47$ & $2.46 \pm 1.18$ & $<0.001$ & NS & $<0.001$ \\
\hline Retroperitoneum & $1.33 \pm 0.78$ & $1.58 \pm 0.36$ & $1.79 \pm 1.47$ & NS & NS & NS \\
\hline Scrotal fat & $1.50 \pm 0.95$ & $0.50 \pm 0.60$ & $1.92 \pm 1.08$ & $<0.02$ & NS & $<0.001$ \\
\hline Total tumor load & $8.00 \pm 1.81$ & $4.25 \pm 1.41$ & $11.79 \pm 3.63$ & $<0.001$ & $<0.001$ & $<0.001$ \\
\hline
\end{tabular}

${ }^{\star} \mathrm{p} 1$ = differences between group $\mathrm{V}$ and $\mathrm{V} ; \mathrm{p} 2$ = differences between group $\mathrm{V}$ and $\mathrm{V}$; $\mathrm{p} 3=$ differences between group $\mathrm{V}$ and $\mathrm{V}$. NS = not significant. 
the trocar at the end of the laparoscopic procedure. Extraction of the tumor through an small incision without protection of the abdominal wall appears to be another variant of direct implantation of tumor cells. ${ }^{13,14}$ Second, it can be hypothesized that insufflation of $\mathrm{CO}_{2}$ in the peritoneal cavity causes turbulence, displacing tumor cells. At the port sites, concentration of tumor cells occurs as a result of the "chimney effect": leakage of $\mathrm{CO}_{2}$ alongside trocars causes a high local gas flow at the trocar sites. The high flow of $\mathrm{CO}_{2}$ may contain aerosols with viable tumor cells, which results in implantation of tumor cells at these sites. ${ }^{15}$ Free intraperitoneal tumor cells occur frequently in digestive cancer as described by Juhl et al., ${ }^{16}$ who showed that $39 \%$ of patients operated on for carcinoma of the stomach, colon, rectum, and pancreas had free intraperitoneal malignant cells. Spreading tumor cells, by manipulation or insufflation of gasses into the peritoneal cavity, appears to affect survival of patients with malignant intraperitoneal tumors. Zirngibl et al. ${ }^{17}$ reported that intraoperative tumor cell spillage reduced the 5-year survival rate after resection of rectal cancer from $70 \%$ to $44 \%$. The third mechanism of development of abdominal wall metastases either is hematogenous or lymphogenous migration of tumor cells to the abdominal wall. This seems unlikely because the blood and lymphatic vessels of the intra-abdominal organs lack an anatomic linkage with the abdominal wall. Moreover, some authors have reported port site metastases without any other evidence of metastases, suggestive of implantation metastasis. ${ }^{18}$

In this study, direct implantation of tumor cells at the EXT site was studied in the solid tumor model. Diffuse and extensive tumor growth was found after 6 weeks in all rats. It was clearly shown that extraction of an unprotected specimen without protection of the abdominal wall enhances tumor growth at the EXT site. To prevent tumor recurrence at the EXT site, the use of plastic bags or wound protectors is recommended to avoid direct contact between the tumor and the wound. ${ }^{19}$ It is essential that extraction of the specimen is done through abdominal incisions wide enough to allow easy passage of the specimen. Furthermore, potentially traumatic manipulation of the tumor by laparoscopic clamps should be avoided by precise preoperative or intraoperative localization of the tumor. This can be achieved using laparoscopic ultrasonography or tattooing of the lesion with Indian ink during colonoscopy before surgery. ${ }^{20}$

The cell seeding model in our study was used to mimic the clinical situation of free intraperitoneal tumor cells. Contrary to the solid tumor model in this experiment, the rats were killed after only 4 weeks, because tumor growth was extensive after 6 weeks in the solid tumor model. To avoid difficult interpretation of tumor growth at separate sites, autopsy was done after 4 weeks. To assess the role of tumor growth induced by $\mathrm{CO}_{2}$ insufflation, tumor growth was compared after gasless and $\mathrm{CO}_{2}$ laparoscopy. In this study, tumor depositions at the trocar sites were significantly greater after $\mathrm{CO}_{2}$ pneumoperitoneum in the cell seeding model. This finding is in accordance with the study by Jones et al., ${ }^{21}$ who found that the trocar site implantation tripled with the addition of pneumoperitoneum. Therefore, turbulence in $\mathrm{CO}_{2}$ laparoscopy appears to be an important factor in the pathogenesis of abdominal wall metastases.

In the cell seeding model in this study, the total tumor load was the greatest after open surgery and the smallest after gasless laparoscopy. A major difference between open and laparoscopic surgery is the degree of operative trauma. The extent of postoperative hormonal, metabolic, and immunologic changes is proportional to the degree of surgical trauma. ${ }^{22}$ Although the influence of immunologic and metabolic changes on tumor biology is unresolved in many cases, tumor growth appears to be proportional to the extent of operative trauma as well. Eggermont et al. ${ }^{23}$ showed in an experimental study that laparotomy promotes tumor growth. Studies on tumor biology after either open or laparoscopic surgery have shown less tumor growth and less tumor take after laparoscopic surgery. ${ }^{24}$ In an experimental study in mice by Allendorf et al., ${ }^{25}$ intradermal tumor growth was greater after open surgery in comparison to laparoscopic surgery. ${ }^{25}$ In an earlier study in rats, we found less tumor take after laparoscopically assisted small bowel resection than after open small bowel resection.

The significant difference of tumor growth between $\mathrm{CO}_{2}$ and gasless laparoscopy as found in this study deserves discussion. The operative trauma appears similar in these two techniques. However, the use of $\mathrm{CO}_{2}$ resulted in greater peritoneal tumor growth. Increased absorption of $\mathrm{CO}_{2}$ is known to be associated with systemic effects such as acidosis, reduction in cardiac stroke volume, and cardiac arrhythmia. ${ }^{26,27}$ Direct effects of $\mathrm{CO}_{2}$ on tumor growth are unknown, although a study by Watson et al. ${ }^{28}$ showed that intraperitoneal macrophage activity was compromised after $\mathrm{CO}_{2}$ insufflation as compared to insufflation with air and laparotomy. The role of $\mathrm{CO}_{2}$ in tumor biology demands further study. In our experiment, hypercapnia and acidosis were not monitored or corrected. Therefore, it remains unresolved if either direct exposure of the peritoneum to $\mathrm{CO}_{2}$ or $\mathrm{CO}_{2}$-induced hypercapnia and acidosis promoted peritoneal tumor growth. Another factor that deserves analysis is the duration and pressure of peritoneal $\mathrm{CO}_{2}$ insufflation. Experimental studies assessing time and pressure dependency of $\mathrm{CO}_{2}$-induced peritoneal tumor growth are necessary. Finally, use of gasses other than $\mathrm{CO}_{2}$ should be evaluated.

Extrapolation of the results of this study to the clinical situation of laparoscopic resection of malignant tumors is limited for several reasons. First, injecting tumor cells 
in the peritoneal cavity is not similar to a localized colorectal cancer. Second, intraperitoneal surgical dissection was minimal and a bowel resection was not performed. Unfortunately, to our knowledge, it has not been possible until now to induce a localized colon cancer in experimental animals. However, recently we have developed in rats a laparoscopic model to remove kidneys with localized tumor. This model allows further study on the effects of gas(less) laparoscopy and laparotomy on tumor biology.

The favorable effects of laparoscopy on tumor growth in this study appear to contradict the great number of reports on port site metastases after laparoscopic resection of colorectal cancer. However, extracting colorectal cancers through narrow incisions, inadvertent grasping of the tumor, and opening of the colon seems to have been a major factor in these cases. In addition, the rate of abdominal wall recurrence after conventional colorectal cancer resections has received limited attention and is therefore likely to be under-reported.

\section{CONCLUSION}

This study showed that in surgery for intraperitoneal cancer, the EXT site of the specimen is at risk and deserves protection. The EXT site should allow easy passage of the specimen. Furthermore, laparoscopic surgery appears to be associated with less tumor growth than with laparotomy, particularly when gasless techniques are used.

\section{References}

1. Dubois F, Icard P, Berthelot G, et al. Coelioscopic Cholecystectomy: preliminary report of 36 cases. Ann Surg 1990; 211:60-62.

2. Ramos JM, Beart RW, Goes R, et al. Role of laparoscopy in colorectal surgery: a prospective evaluation of 200 cases. Dis Colon Rectum 1995; 38:494-501.

3. Frazee RC, Roberts JW, Symmonds RE, et al. A prospective randomized trial comparing open versus laparoscopic appendectomy. Ann Surg 1994; 219:725-731.

4. Glerup $\mathrm{H}$, Heindorff $\mathrm{H}$, Flyvbjerg A, et al. Elective laparoscopic cholecystectomy nearly abolishes the postoperative hepatic catabolic stress response. Ann Surg 1995; 221:214-219.

5. Beart RW. Laparoscopic colectomy: status of the art. Dis Colon Rectum 1994; 37(Suppl):S47-S49.

6. Cirocco WC, Schwartzman A, Golub RW. Abdominal wall recurrence after laparoscopic colectomy for colon cancer. Surgery 1994; 116:842-846.

7. Wexner SD, Cohen SM. Port site metastases after laparoscopic colorectal surgery for cure of malignancy. Br J Surg 1995; 82:295298.

8. Berends FJ, Kazemier G, Bonjer HJ, et al. Subcutaneous metastases after laparoscopic colectomy. Lancet 1994; 344:58 (Letter).

9. Hughes ES, McDermott FT, Poliglase AI, et al. Tumor recurrence in the abdominal wall scar after large bowel cancer surgery. Dis Colon Rectum 1983; 26:571-572.

10. Prehn RT, Main JW. Immunity to methylcholanthrene induced sarcomas. J Natl Cancer Inst 1957; 18:769-778.
11. Steller EPH. Enhancement and Abrogation. Modifications of host immune status influence IL-2 and LAK cell immunotherapy. Rotterdam, The Netherlands: Erasmus University Rotterdam; 1988. Thesis (pp 34-43).

12. Hoffman GC, Baker JW, Fitchett CW, et al. Laparoscopic-assisted colectomy-initial experience. Ann Surg 1994; 219:732-743.

13. Murphy $P$, Alexander P, Senior PV, et al. Mechanisms of organ selective tumor growth by bloodborne cancer cells. Br J Cancer 1988; 57:19-31.

14. Savalgi RS. Mechanism of abdominal wall recurrence after laparoscopic resection of colonic cancers. Seminars in Laparoscopic Surgery $1995 ; 2: 158-162$.

15. Kazemier G, Bonjer HJ, Berends FJ, et al. Port site metastases after laparoscopic colorectal surgery for cure of malignancy. Br J Surg 1995; 82:1141-1142 (Letter).

16. Juhl H, Stritzel M, Wroblewski A, et al. Immunocytochemical detection of micro-metastatic cells: comparative evaluation of findings in the peritoneal and pancreatic cancer patients. Int J Cancer 1994; 57:330-335.

17. Zirngibl H, Husemann B, Hermanek P. Intraoperative spillage of tumor cells in surgery for rectal cancer. Dis Colon Rectum 1990; 33:610-614.

18. O'Rourke N, Price PM, Kelly S, et al. Tumor inoculation during laparoscopy. Lancet 1993; 342:368 (letter).

19. Phillips EH, Franklin M, Carroll BJ, et al. Laparoscopic colectomy. Ann Surg 1992; 216:703-707.

20. Botoman VA, Pietro M, Thirlby RC. Localization of colonic lesions with endoscopic tattoo. Dis Colon Rectum 1994; 37:775-776.

21. Jones DB, Guo L-W, Reinhard MK, et al. Impact of pneumoperitoneum on trocar site implantation of colon cancer in hamster model. Dis Colon Rectum 1995; 38:1182-1188.

22. Griffith JP, Everitt NJ, Lancaster F, et al. Influence of laparoscopic and conventional cholestyctectomy upon cell-mediated immunity. Br J Surg 1995; 82:677-680.

23. Eggermont AM, Steller EP, Marquet RL, et al. Local regional promotion of tumor growth after abdominal surgery is dominant over immunotherapy with interleukin-2 and lymphokine activated killer cells. Cancer Detect Prev 1988; 12:421-429.

24. Bouvy ND, Marquet RL, Hamming JF, et al. Laparoscopic surgery in the rat: beneficial effect on bodyweight and tumor take. Surg Endosc 1996; 10:490-494.

25. Allendorf JDF, Bessler M, Kayton ML, et al. Increased tumor establishment and growth after laparotomy vs laparoscopy in a murine model. Arch Surg 1995; 130:649-653.

26. Holzman M, Sharp K, Richards W, et al. Hypercarbia during $\mathrm{CO}_{2}$ gas insufflation for therapeutic laparoscopy: a note of caution. Surg Laparosc Endosc 1992; 2:11-14.

27. Minoli G, Terruzzi V, Tadeo G, et al. Laparoscopy: the question of a proper gas. Gastrointest Endosc 1983; 29:325.

28. Watson RWG, Redmond HP, McCarthy J, et al. Exposure of the peritoneal cavity to air regulates early inflammatory responses to surgery in a murine model. Br J Surg 1995; 82:1060-1065.

\section{Discussion}

J. Collin (Oxford, United Kingdom): Very interesting paper. May I suggest that the problem is not insufflation of carbon dioxide but the mode of its evacuation. My question is this: Did you allow the cannulas to stay in place until all the carbon dioxide had been evacuated from the peritoneal cavity or were the cannulas removed when there was still $\mathrm{CO}_{2}$ in the abdomen? I think the problem may be that rapid escape of $\mathrm{CO}_{2}$ through an unsheathed cannula port 